\title{
Serum magnesium in diabetic retinopathy: relation to glycated haemoglobin and lipid profile
}

\author{
Amjad H. Al- Naemi \\ Department of Biochemistry, \\ College of Medicine, University of Mosul,
}

\begin{tabular}{|c|c|}
\hline Received: & Accepted \\
\hline rı.^.r..人 & r.11.r. \\
\hline
\end{tabular}

\begin{abstract}
The aim of this study was to evaluate serum magnesium status in diabetic retinopathy and to investigate its relation to serum lipid profile and glycated haemoglobin $(\mathrm{HbAlc})$ as a marker for longterm metabolic control in diabetes. The current case control study has enrolled ro type $r$ diabetics without retinopathy (Group I), ro diabetics with retinopathy (Group $r$ ) and $r$ ) apparently healthy nondiabetic control subjects (Group $r$ ). Overnight fasting serum magnesium, lipid profile and $\mathrm{HbA} / \mathrm{c}$ concentration were analyzed for all subjects. The mean serum magnesium level was significantly lower in Group $(r)$ compared to that of Group ' $(p<\because \cdots)$ ). The mean serum triglycerides (TGs) and HbA 'c levels were significantly higher in Group $r(p<\ldots \ldots)$. No statistically significant differences were noticed comparing the mean serum total cholesterol (TC) and LDL-cholesterol concentrations in both groups 1 and $r(p>\cdot . \cdot 0)$.

The study revealed a significant negative correlation between serum magnesium on one hand and serum TGs, TC, LDL- cholesterol and HbA'c on the other hand where $r=-\cdot .7 \leqslant 7,-\cdot . \leqslant \vee,-\cdot r r o$, and $\cdot . \wedge$ ro respectively. Meanwhile serum magnesium was significantly and positively correlated with HDLcholesterol levels $(r=\cdot r q 0, p>\cdot, \cdot)$ ). Using Forward Stepwise Multiple Regression analysis, the study revealed that hypomagnesaemia, poor glycaemic control and increasing duration of diabetes are the most important contributors to the cumulative risk for the development of diabetic retinopathy (Odds ratios $17.70,077$ and $V . r 7$ respectively).

In conclusion, magnesium depletion is a significant risk factor for, and a frequent finding in, diabetic retinopathy beside poor glycaemic control, dyslipidaemia (mainly hypertriglyceridaemia), and increasing duration of uncontrolled diabetes. The significant association between hypomagnesaemia and high fasting serum levels of TGs, TC, LDL-cholesterol and $\mathrm{HbA}$ 'c would rather support the suggested role for magnesium depletion in the metabolic derangements associated with retinopathy in diabetic patients. Further studies on the effects of magnesium supplementation for diabetic patients are necessary to investigate the spectrum of metabolic improvements following magnesium therapy and the degree to which the risk of diabetic retinopathy might be reduced.
\end{abstract}

Keywords: diabetic retinopathy, hypoglycemia, lipid prfile.

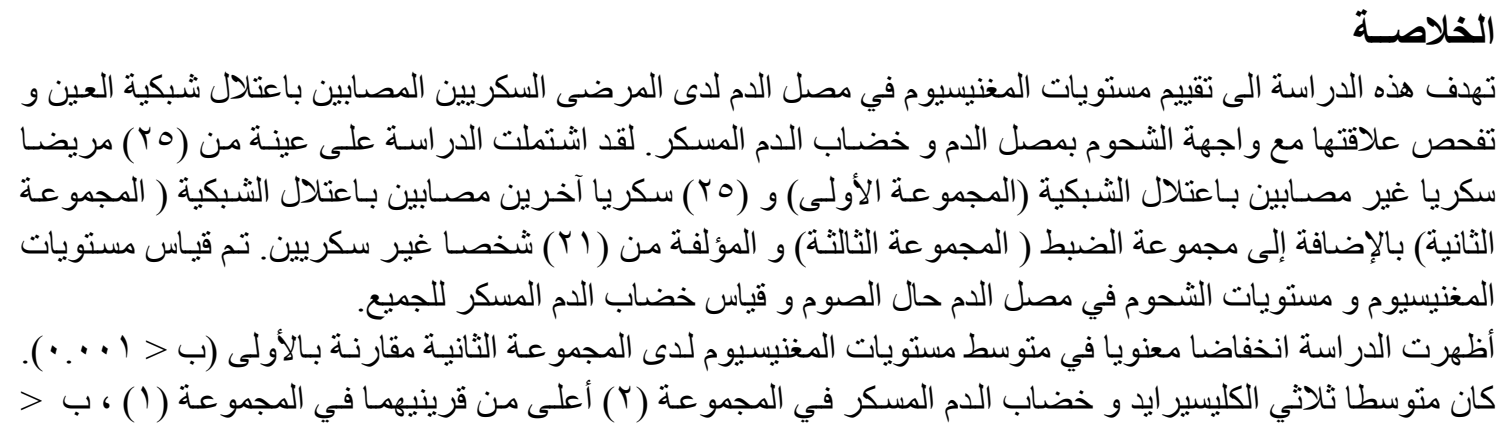




$$
\begin{aligned}
& \text { ا .... . . لم تظهر الدر اسة فروقا معنوية عند مقارنة منوسطي (إجمالي الكوليستيرول) و (الكوليستيرول ضمن البروتين }
\end{aligned}
$$

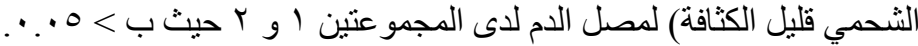

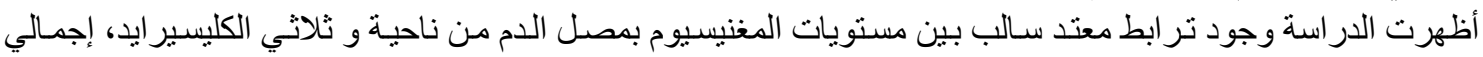

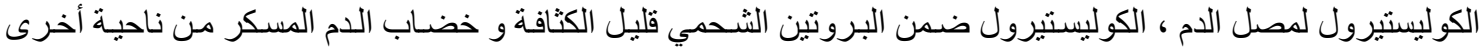

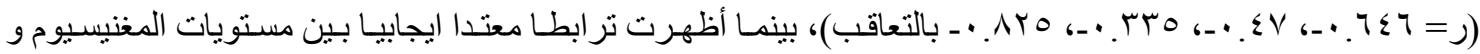

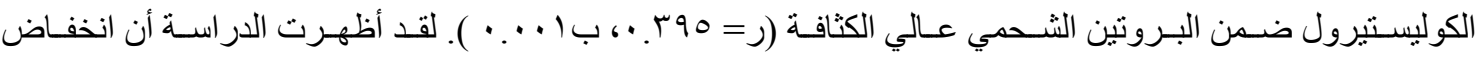

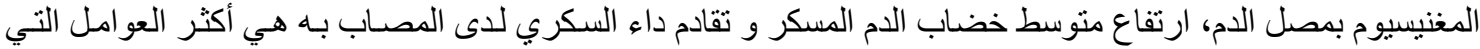

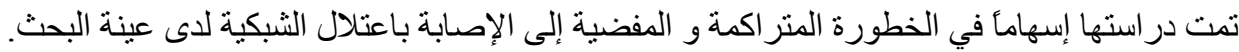

$\mathbf{M}$ predominant $\begin{aligned} & \text { agnesium } \\ & \text { component in the }\end{aligned}$ intracellular compartment, an important regulator of many cellular processes, and a cofactor of more than $r .$. essential metabolic reactions including those which utilize or produce Mg ATP complex.' It has been recently pointed out that $\mathrm{Mg}$ deficiency is related to several life style- related diseases, such as hypertension, hyperlipidaemia, and ischemic heart disease. ${ }^{r} r$ Magnesium plays an important role in carbohydrate metabolism and its imbalance has been implicated in diabetes mellitus (DM) as a cause and a consequence .

A large body of evidence has been progressively accumulated in the past years that shows a link between hypomagnesaemia and reduction of tyrosine- kinase activity at the insulin receptor level, which may result in the impairment of insulin action. ${ }^{\mathrm{r}-9}$. In this way hypomagnesaemia has been regarded as a cause for insulin resistance, although however being a consequence of hyperglycaemia which, independent of insulin or other responses due to oral glucose ingestion has a potential role in cellular ionic changes of free calcium and Mg. '. The low availability of intracellular Mg does not only diminish tyrosin- kinase activity but also increases vascular constriction mediated by calcium and thus interfering with the usage of the cellular glucose. Such mechanisms contribute to both increased blood pressure and insulin resistance.", "

The association between DM and hypomagnesaemia is compelling for its wide ranging impact on diabetic control and complications. ". The chronic complications of diabetes develop when cells are chronically exposed to hyperglycaemia. The non- enzymatic glycosylation of cellular proteins and the accumulation of polyol as sorbitol result in the formation of the end products of advanced glycosylation in different tissues. This process aids to trigger macrovascular complications like dyslipdaemia atherosclerosis, hypertension and microvascular complications like neuropathy, nephropathy and retinopathy. 'r. Advanced glycosylation end products are thought to play a major pathogenic role in diabetic retinopathy ${ }^{(i r)}$.

Magnesium depletion has been linked to the development of diabetic retinopathy., ${ }^{\{, 1,1 \text {, }}$ Although strict metabolic control in diabetes is believed to delay the development of late complications, it has been demonstrated conclusively that such a control restrains the development of retinopathy in diabetic patients. 
This study aims to study serum magnesium status in relation to glycated haemoglobin $\left(\mathrm{HbA} \mathrm{C}^{\prime}\right)$ and serum lipid profile in patients with diabetic retinopathy.

\section{Patients and methods}

This is a case- control study that was carried out over a period of $r$ months started from May $1^{\text {st }}$. to July $r 1^{\text {st }}, r \cdots \wedge$. It enrolled a randomly selected sample of known cases of type $r$ DM who are regularly attending "Al- Wafaa Center for Diabetes Treatment and Research" in Western Mosul.

Patients who agreed to participate in the study were referred for ophthalmological assessment by a specialist in the "Ophthalmology Outpatient Clinic" in AlJumhory Teaching Hospital. They were assessed for the presence or absence of diabetic retinopathy using direct and indirect ophthalmoscopy. Subjects with hypertension, chronic diahroea, and/ or on diuretics were excluded from the study.

Finally, based on the ophthalmological assessment, a randomly selected group of ro diabetic patients without retinopathy (1) males and 1 \& females) formed Group ( 1 ) and another group of ro diabetics with retinopathy (10 males and $1 \cdot$ females) joined Group $(r)$.

A control group of $r$ ) subjects ( 1 ) males and 1 . females) was randomly selected for comparison forming Group r. They were apparently healthy age and sex matched non- diabetic individuals who agreed to be the control volunteers in this study.

A six- $\mathrm{ml}$ blood sample was collected from all diabetic and non- diabetic participants following overnight fasting. EDTA tubes were used to collect around one- half $\mathrm{ml}$ whole blood specimens which were kept refrigerated at $r-\wedge C^{\circ}$ for estimation of glycated haemoglobin $\left(\mathrm{HbA}^{\prime} \mathrm{c}\right)$ in weekly batches. The remaining blood was collected in plain tubes, allowed to clot and serum was separated by centrifugation at $r \ldots$ rpm for $1 .-10$ minutes and kept frozen at $-r \cdot c^{0}$ for the estimation of serum lipids and magnesium in weekly batches as well. Specimens handling and biochemical measurements were carried out in the Laboratory of Clinical Biochemistry, Department of Biochemistry, Mosul Medical College.
The estimation of $\mathrm{HbAlc}$ was done using a modified quantitative colorimetric method with the use of a kit purchased from Stanbio Laboratory (USA). In this method a preparation of haemolyzed whole blood is mixed with binding cation- exchange resin. The nonglycated haemoglobin $\left(\mathrm{HbA}^{\circ}\right)$ binds to the resin leaving $(\mathrm{HbA})$ ) free to be removed by means of a resin separator in the supernatant. Results were directly reported as $\mathrm{HbAl}^{\prime c}$ using the standard concentration of $\mathrm{V} .7 \%$.

Serum magnesium was measured using Gindler, Heth and Khayam- Bashi method ${ }^{(10,17)}$ where calmagite, a metallochromic indicator forms a colored complex with magnesium in basic medium. The measured absorbance is proportional to magnesium concentration in the specimen. Magnesium assessment was done using a kit purchased from Biolabo (France).

Determination of serum total cholesterol (TC), high density lipoprotein cholesterol (HDL-C) and triglycerides (TGs) was performed using enzymatic methods ${ }^{(' v)}$. Low density lipoprotein cholesterol (LDL- C) was calculated using Friedwald formula for those with serum triglycerides < $\leqslant .0 \mathrm{mmol} / \mathrm{L}$ where LDL- C $(\mathrm{mmol} / \mathrm{L})=\mathrm{TC}-(\mathrm{HDL}-\mathrm{C}+\mathrm{TG} \times \cdot . \leqslant 00)^{(1 \wedge)}$.

The statistical analysis used in this study included the standard statistical methods to determine the mean, standard deviation (SD), and range (minimum - maximum). Unpaired Student's t- test was used to compare the mean values of the studied parameters. In addition, the association between the biochemical markers studied was done using linear regression analysis. Forward Stepwise (Conditional) Multiple Regression analysis was performed and the Odds ratios were calculated for the studied parameters as a reflection for their contribution to the risk of development of diabetic retinopathy. Differences between observations were considered not significant as p>... .

\section{Results}

The results of the analyzed data are presented according to the grouping of subjects enrolled in this study. Fifty known cases of type $r$ diabetes mellitus (DM) and other $r$ apparently healthy age and sex matched non-diabetic subjects 
formed the three study groups and these groups are:

\section{Group 1.. Diabetics without Retinopathy}

It included ro type $r$ diabetic subjects ( 1 males and 1 \& females) proved not to have retinopathy as assessed by direct and indirect ophthalmoscopy. They aged $\leqslant \cdot-i v$ years (mean or. $\wedge \pm \vee . r \wedge$ years). Their history of having DM ranged between $1-i V$ years with the mean duration of $\varepsilon . \wedge \varepsilon \pm r .79$ years.

The mean serum magnesium concentration for patients in this group was $\cdot . V 1 \pm \cdot .17 \mathrm{mmol} / \mathrm{L}$ (range $\cdot . \$ 1-.99 \mathrm{mmol} / \mathrm{L}$ ). On the other hand, fasting serum triglycerides levels ranged

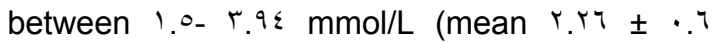
$\mathrm{mmol} / \mathrm{L})$.

The mean serum total cholesterol level was

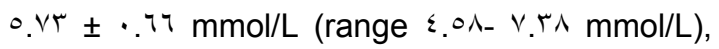
while that of HDL- Cholesterol levels was 1. IV \pm - rr mmol/L (range . . $\wedge r-1 . \vee \leqslant \mathrm{mmol} / \mathrm{L}$ ). Lowdensity lipoprotein - cholesterol (LDL- C) values estimated using Friedwald's formula ranged

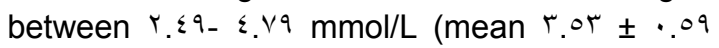
$\mathrm{mmol} / \mathrm{L}$ ). The mean $\mathrm{HbA})^{\prime c}$ level for patients in this group was $1 . .0 \% \pm 1.9$ (range 0.97 $1 . .1 \%)$.

\section{Group $r$. Diabetics with Retinopathy}

This group is composed of ro type $r$ diabetics with changes of diabetic retinopathy in either one or both eyes i.e having microaneurysms with exudates, hemorrhages and vascular proliferative changes. They were 10 males and

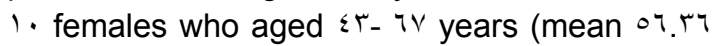
\pm 0.97 years). They had DM for a period ranged between $r-r v$ years (mean $M . r Y \pm T, Y \varepsilon$ years).

Compared to patients in group ( 1 ), the mean serum magnesium concentration for patients in this group was $\cdot .0 \mathrm{~V} \pm . .11 \mathrm{mmol} / \mathrm{L}$ (range $\cdot$. . . $) ~ \mathrm{mmol} / \mathrm{L}$ ). However, serum triglycerides levels ranged between $r . \cdot 1-0 . r^{q} \mathrm{mmol} / \mathrm{L}$ with the mean of $r . r^{\prime} \pm \cdot . \wedge r \mathrm{mmol} / \mathrm{L}$ and the mean serum total cholesterol level was $7.1 v_{ \pm} . .91$ $\mathrm{mmol} / \mathrm{L}$ (range $0.10-\Lambda .4 \mathrm{mmol} / \mathrm{L}$ ).

High density lipoprotein - cholesterol levels ranged between $\cdot . \wedge \wedge-1 . r \vee \mathrm{mmol} / \mathrm{L}$ with the mean concentration of $1 . \cdot \varepsilon \pm \cdot .1 \wedge \mathrm{mmol} / \mathrm{L}$, while LDL- $C$ values ranged between r.r. $0.0 r$ $\mathrm{mmol} / \mathrm{L}$ with the mean of $r . v r \pm \cdot .9 \leq \mathrm{mmol} / \mathrm{L}$.
However, the mean $\mathrm{HbAlc}$ level in this group was $1 . . v \% \% \pm 1.11$ (range 1.90 - $1 r \%$ ).

\section{Group r. Control Group}

This group is composed of $r$ apparently healthy non- diabetic subjects who volunteered to participate in this study as a control sample. They were 11 males and 1 . females with a mean age of $01.1 \pm \Lambda . V r$ years (range rq- 10 years). Initially, they were $r_{0}$ subjects ( $I \leqslant$ males and 11 females) with negative family history of diabetes and a recent normal fasting plasma glucose testing. However, upon testing their $\mathrm{HbA}$ 'c values, $\varepsilon$ of them ( $r$ males and 1 female) exhibited elevated concentrations of glycosylated hemoglobin (more than $7 . r \%$ ) reflecting abnormal glycemic status and thus were excluded from the control group.

Their fasting serum concentrations of $\mathrm{Mg}$, TGs, TC, HDL- $C$ and LDL- C were $.9 \mathrm{~V} \pm . . \mathrm{V}$ $\mathrm{mmol} / \mathrm{L}$ (range $\cdot . V_{-}-1 . r \circ \mathrm{mmol} / \mathrm{L}$ ),, $1 . r q \pm \cdot r q$ $\mathrm{mmol} / \mathrm{L}$ (range $\cdot . \wedge v_{-} r .17 \mathrm{mmol} / \mathrm{L}$ ), $\varepsilon . \vee \varepsilon \pm \cdot . \wedge$. $\mathrm{mmol} / \mathrm{L}$ (range $r . \varepsilon r-r . T \wedge \mathrm{mmol} / \mathrm{L}$ ),, $1 . r^{\prime} \pm \cdot . r r$ $\mathrm{mmol} / \mathrm{L}$ (range $.9 r-1 . \vee 9 \mathrm{mmol} / \mathrm{L}$ ) and r.10 \pm $.71 \mathrm{mmol} / \mathrm{L}$ (range $1.7{ }_{-} \quad r .99 \mathrm{mmol} / \mathrm{L}$ ) respectively. However, the mean $\mathrm{HbAlc}$ concentration in this group was $0.0 \% \pm .7 \mathrm{~h}$ (range s. 11- . . r. \%).

Unpaired Student's t- test was used to compare the mean values for the measured serum biochemical parameters and $\mathrm{HbA} / \mathrm{c}$ between diabetics in Group ( 1 ) i.e. those without retinopathy and those in Group $(r)$ i.e. those with retinopathy on one hand, and between patients in group ( 1 ) and the control group (Group ${ }^{\top}$ ) on the other hand.

This test revealed that the mean serum magnesium was significantly lower in group $r$ compared to that for those in Group $1(t=r .0 \leqslant 7$, $\mathrm{p}<. \cdots 1)$. Meanwhile, statistically significant differences were also seen in the mean serum TGs, HDL- C, and $\mathrm{HbA})^{\mathrm{c}}$ comparing both $(\mathrm{t}=$ $\varepsilon . q, p<. \cdots \cdot ; t=r . r q, p<\cdot . .0 ; t=\Lambda .01, p<$ $\because \ldots)$ respectively). No statistically significant differences were noticed in the mean serum total cholesterol and serum LDL- $C$ concentrations comparing the two groups $(p>\cdot . \cdot 0)$. Besides the comparison of the biochemical markers, this test revealed a significant statistical difference in 
the mean duration of diabetes among patients without and those with retinopathy $(\mathrm{t}=0.17, \mathrm{p}<$ $\because . .1$ ).

This test was applied again to compare the same parameters between diabetics without retinopathy (Group 1) and the control subjects in Group ( $($ ). All comparisons of almost all biochemical parameters (including serum total cholesterol and LDL- C) showed significant statistical differences in their mean values. The mean $\pm S D$ values for serum magnesium, triglycerides, total cholesterol, HDL- C, LDL- C, and $\mathrm{HbA}{ }^{\prime} \mathrm{C}$ of the three study groups are shown in Table ( $)$.

Linear regression analysis was then applied to study the relationship between serum magnesium, which is the main target biochemical marker in this work, and other measured parameters. The analysis was applied for all subjects in the three study groups so that changes in the dependent and thus those in the independent biochemical variables would be more clear and evident. The analysis revealed a significant inverse relationship between serum magnesium and TGs $(r=\ldots .7 \leqslant 7, p<\cdot . \cdot 1)$, TC $(r=-\cdot \varepsilon v, p<\because \cdots)$, LDL- cholesterol $(r=-$ .rro, $p=\cdot \cdots \varepsilon)$, and $\mathrm{HbA} / \mathrm{c}\left(\mathrm{r}=-. \wedge \mathrm{ro}_{\mathrm{O}}, \mathrm{p}<\right.$ $\because \cdots 1)$. However, a significant positive correlation was noticed between serum magnesium and serum HDL- cholesterol concentrations $(r=\cdot r 90, p=\cdot \cdots 1)$. Results of linear regression analysis are illustrated in Figures $1, r, r$, $\varepsilon$ and $\bullet$.

The variables of concern (the biochemical items beside the duration of diabetes) were further assessed as their contribution to the risk for the development of diabetic retinopathy using "Forward Stepwise (Conditional) Multiple Regression Analysis" after standardization of data that belong to all type $r$ diabetic subjects enrolled in this study. This test revealed that the duration of DM in addition to hypomagnesaemia and poor glycaemic control (expressed as high $\mathrm{HbA} / \mathrm{c}$ concentrations) are the most important contributors for the development of diabetic retinopathy for patients examined. The coefficients of logistic regression, odds ratios and the $90 \%$ confidence intervals for the above three important correlates are shown in Table $(r)$.

Table '. Results (mean $\pm S D$ ) of serum magnesium, lipid profile and glycated haemoglobin $(H b A)$ ) in the three study groups.

\begin{tabular}{|c|c|c|c|c|c|c|}
\hline Groups & $\begin{array}{c}\text { Serum } \\
\text { Magnesium } \\
(\mathrm{mmol} / \mathrm{L})\end{array}$ & $\begin{array}{c}\text { Serum } \\
\text { Triglycerides } \\
(\mathrm{mmol} / \mathrm{L})\end{array}$ & $\begin{array}{c}\text { Serum } \\
\text { Total } \\
\text { Cholesterol } \\
(\mathrm{mmol} / \mathrm{L})\end{array}$ & $\begin{array}{c}\text { Serum } \\
\text { HDL- Cholesterol } \\
(\mathrm{mmol} / \mathrm{L})\end{array}$ & $\begin{array}{c}\text { Serum } \\
\text { LDL- } \\
\text { Cholesterol } \\
\text { (mmol/L) }\end{array}$ & $\begin{array}{c}\mathrm{HbA}^{\prime} \mathrm{c} \\
(\%)\end{array}$ \\
\hline $\begin{array}{c}\text { Group I } \\
\text { (Diabetics withou } \\
\text { retinopathy) } \\
\left(n=r_{0}\right)\end{array}$ & $.81 \pm \cdot .17$ & Y.Y & $0 . \mathrm{VT} \pm \cdot .74$ & $1.1 V \pm \cdot . r r$ & $r .0 r \pm \cdot .09$ & $1 . \cdot 0 \pm 1 . \cdot 9$ \\
\hline $\begin{array}{l}\text { Group r } \\
\text { (Diabetics with } \\
\text { retinopathy) } \\
\left(n=r^{\circ}\right)\end{array}$ & $.0 v \pm \cdot .11$ & 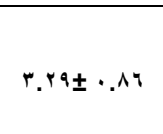 & $7.1 V \pm \cdot .91$ & $1 . \cdot \leq \pm \cdot .11$ & $r . V r \pm \cdot . q \leq$ & $1 \cdot . V T \pm 1.11$ \\
\hline $\begin{array}{c}\text { Group r } \\
\text { (Control Group) } \\
\left(n=r^{\prime}\right)\end{array}$ & $\cdot .9 V \pm \cdot .1 V$ & $1 . r q \pm \cdot . r q$ & $\varepsilon . V \leqslant \pm \cdot . \Lambda$ & $1 . r 9 \pm \cdot . r r$ & $r . \wedge \bullet \pm \cdot . \Upsilon \wedge$ & $0.0 \pm \cdot .71$ \\
\hline p- Value & $\begin{array}{l}<\cdot \cdots 1^{*} \\
<\left.\cdot \ldots\right|^{* *}\end{array}$ & $\begin{array}{l}<\left.\cdot \cdots\right|^{*} \\
<\cdot \ldots+* *\end{array}$ & $\begin{array}{l}>\cdot .0^{*} \\
<\cdot \ldots \cdot)^{* *}\end{array}$ & $\begin{array}{l}<\cdot \cdot 0^{*} \\
<\cdot \ldots \cdot * *\end{array}$ & $\begin{array}{l}>\cdot . \cdot 0 * \\
<\cdot \ldots \cdot 1 * *\end{array}$ & $\begin{array}{l}<\left.\ldots \ldots\right|^{*} \\
<\left.\ldots \ldots\right|^{* *}\end{array}$ \\
\hline
\end{tabular}

* Group r Vs. Group 1, ** Group IVs. Group r 
Table r. Results of Forward Stepwise (Conditional) Multiple Regression analysis of studied variables as risk factors for diabetic retinopathy in the studied patients.

\begin{tabular}{|c|c|c|c|}
\hline & $\begin{array}{c}\text { Coefficient of Logistic } \\
\text { Regression }\end{array}$ & p-Value & Odds Ratio \\
\hline Duration of Diabetes & 1.997 & $<\cdot . \bullet$ & V.ru \\
\hline Serum Magnesium & r.AIr & $<\cdot .0$ & 17.70 \\
\hline $\mathrm{HbA}{ }^{\prime c} \mathrm{c}$ & $7 . r \varepsilon$ & $<\cdot \cdot 1$ & 074 \\
\hline
\end{tabular}

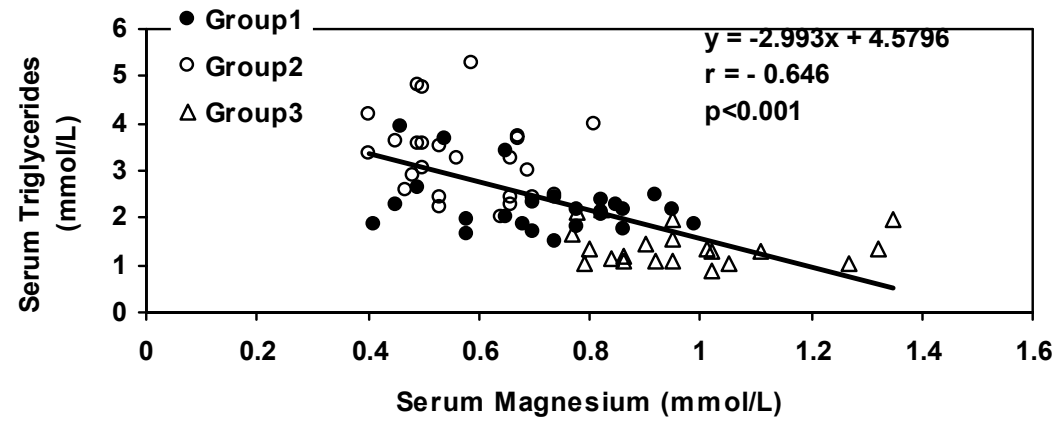

Figure '. Linear regression analysis of serum magnesium $(\mathrm{mmol} / \mathrm{L})$ and serum triglycerides $(\mathrm{mmol} / \mathrm{L})$ in the study groups.

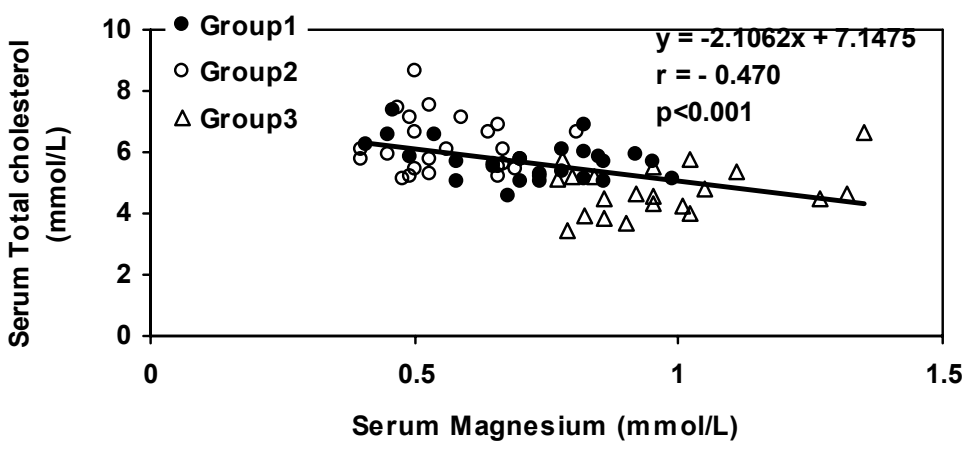

Figure r. Linear regression analysis of serum magnesium ( $\mathrm{mmol} / \mathrm{L}$ ) and serum total cholesterol ( $\mathrm{mmol} / \mathrm{L}$ ) in the study groups.

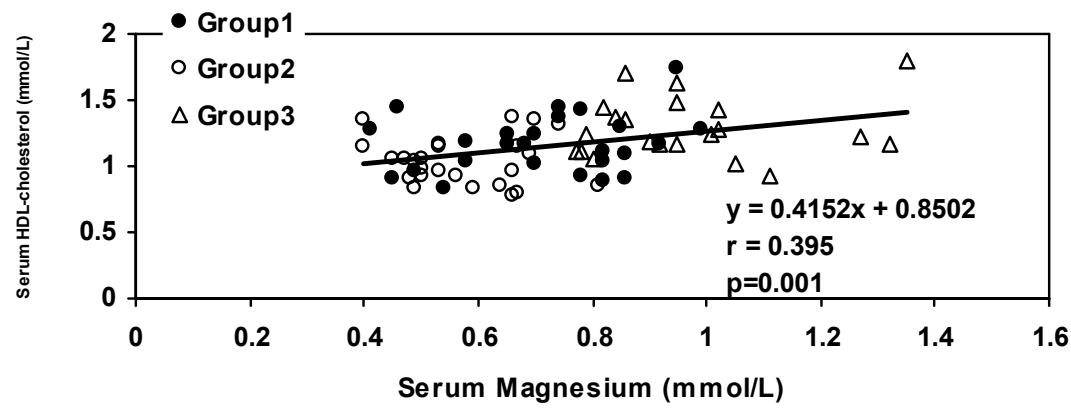

Figure r. Linear regression analysis of serum magnesium ( $\mathrm{mmol} / \mathrm{L})$ and serum $\mathrm{HDL}$ - cholesterol $(\mathrm{mmol} / \mathrm{L})$ in the study groups. 


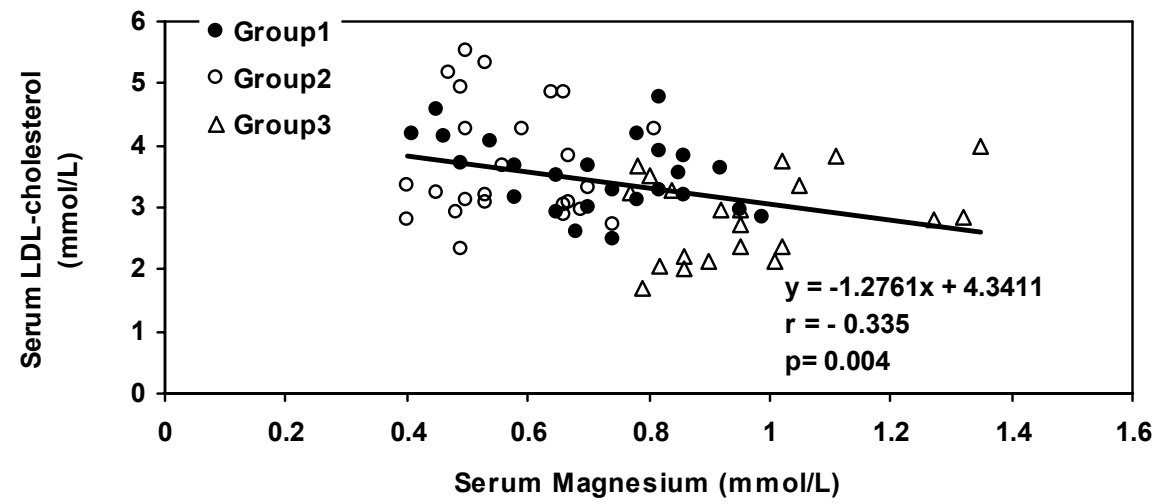

Figure $\varepsilon$. Linear regression analysis of serum magnesium ( $\mathrm{mmol} / \mathrm{L}$ ) and serum LDL- cholesterol ( $\mathrm{mmol} / \mathrm{L}$ ) in the study groups.

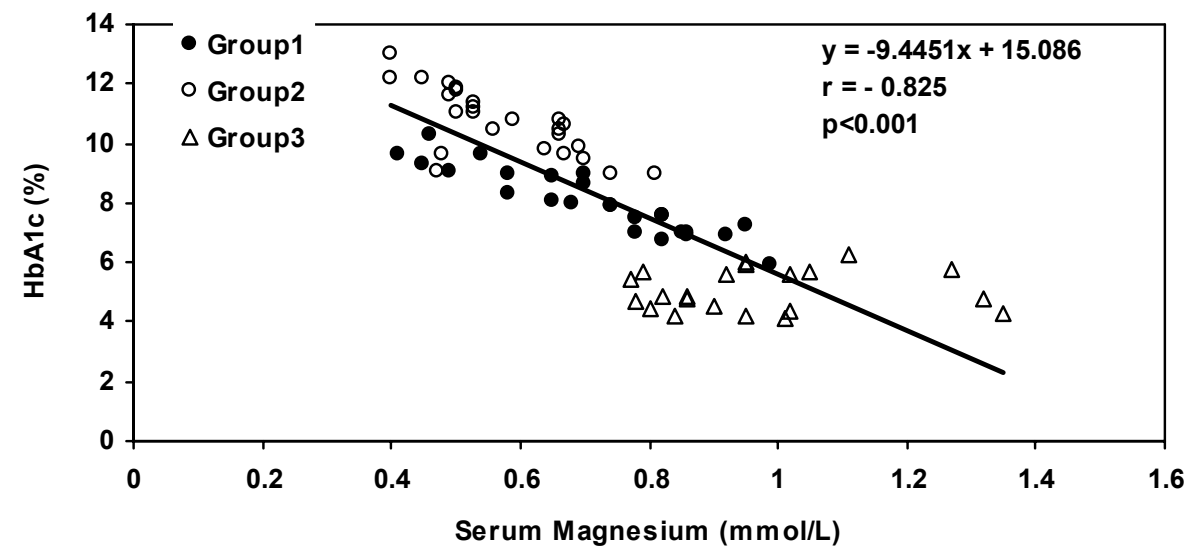

Figure 0 . Linear regression analysis of serum magnesium ( $\mathrm{mmol} / \mathrm{L})$ and $\mathrm{HbA} / \mathrm{c}(\%)$ in the study groups.

\section{Discussion}

The tendency to hypomagnesaemia in patients with diabetes mellitus may be attributed to glycosuria- related magnesiuria, nutritional factors and/or hyperinsulinaemia. ${ }^{19}$ Several large observational studies, including the Atherosclerosis Risk in Communities (ARIC) Study have demonstrated a strong crosssectional association between serum magnesium levels and type $r$ diabetes. ${ }^{\wedge}, r \cdot r r$ Hypomagnesaemia could be involved in the development of poor metabolic control and chronic diabetic sequels including both macro and microangiopathic complications. ${ }^{\text {, }} r$. Of these chronic microvascular complications, magnesium depletion has been linked to the development of retinopathy ${ }^{\varepsilon, 11,1 \xi}$
The pathogenesis of diabetic retinopathy is not completely understood, but established risk factors include poor glycaemic control, hypertension, increasing age, and duration of diabetes. $^{r \xi}$ Moreover; besides magnesium depletion, several cross- sectional studies have shown positive association between diabetic retinopathy and conventional plasma lipid profile $\left(r_{0}, r^{\prime}\right)$. Hence, this study highlighted the serum magnesium status and the serum lipid profile in relation to levels of glycated haemoglobin $\left(\mathrm{HbA}^{\prime} \mathrm{c}\right)$ as an index for the long term metabolic control in a group of type $r$ diabetics with retinopathy compared to another group of diabetics without it.

This study revealed that diabetic patients with retinopathy exhibited a significantly lower 
mean serum magnesium concentration compared to those without retinopathy $\left(\cdot .0 V_{ \pm}\right.$ $.11 \mathrm{mmol} / \mathrm{L}$ Vs. $\left.\cdot V^{\prime} \pm .17 \mathrm{mmol} / \mathrm{L}, \mathrm{p}<\cdot . \cdot 1\right)$. Meanwhile, the mean serum magnesium level in diabetics without retinopathy was much lower than that of the control group $(\cdot V) \pm \cdot .17 \mathrm{mmol} / \mathrm{L}$ Vs. $\left..9 v_{ \pm} \cdot .1 \mathrm{r} \mathrm{mmom} / \mathrm{L}, \mathrm{p}<\cdot \ldots l\right)$. These findings are in agreement with those revealed by other workers. I $\&$, iv Consequently, these findings would rather support the suggestion that hypomagnesaemia is a possible risk factor for the development, severity, and progress of diabetic retinopathy.

Beside the overt magnesium depletion in diabetics with retinopathy, and as an established metabolic fact in diabetes mellitus, the impact of poor glycaemic control on the development of diabetic microangiopathy was obvious in this work. This is evident by the high figure of $\mathrm{HbA} / \mathrm{c}$ mean value in diabetic patients with retinopathy compared to those diabetics who did not have it

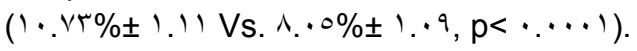

Glycated haemoglobin ( $\mathrm{HbA} / \mathrm{c}$ ) has a special affinity for oxygen thereby causes increasing tissue hypoxia and thus plays an important role in the causation of macro and microangiopathic complication of diabetes. ${ }^{r}$. Furthermore, both of the Diabetes Control and Complications Trial (DCCT) study and the UK Prospective Diabetes Study (UKPDS) have shown a reduction in the risk of diabetic complications with the reduction of $\mathrm{HbAlc}$. ${ }^{r q}, r$ Concerning retinopathy, the DCCT revealed that a sustained reduction of $\mathrm{HbA}$ ) c from $9 . \%$ to $\mathrm{V} . \%$ over 7.0 years led to a reduction in the risk of developing retinopathy of about $\vee r \%$. $^{r q}$

The current work showed a statistically significant negative correlation between the levels of serum magnesium and $\mathrm{HbA}$ 'c values $(r=-\cdot \wedge l r, p<\cdot \cdots)$. This finding was already shown in other studies.

Many studies over the past years have suggested a relationship between serum lipid levels and diabetic retinopathy. It has been postulated that elevation of blood viscosity and alterations in the fibrinolytic system occurs in hyperlipidaemia would cause hard exudates formation. $^{r "}$. On the other hand, triglycerides incorporation into the cell membranes leads to changes in membrane fluidity and leakage of

r... Mosul College of Pharmacy plasma constituents into the retina resulting in hemorrhages and oedema in the retina. ${ }^{r r}$

The present study revealed that type $r$ diabetics who have developed retinopathy exhibited extremely higher mean fasting serum TGs levels compared to diabetics without retinopathy ( $r . \varphi^{9} \pm$

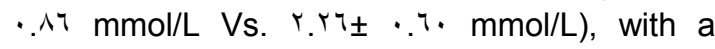
statistically significant difference at $p<\ldots \cdots$. Although it is obvious that the mean values of serum TC and LDL- cholesterol concentrations in diabetics with retinopathy were higher than those in diabetics without retinopathy (despite the absence of significant statistical differences, $p>. .0$ ), but however, like serum TGs; serum HDL- cholesterol levels were found to exhibit a statistically significant difference comparing both groups (mean $1 . \cdot \varepsilon_{ \pm} \cdot .1 \wedge \mathrm{mmoml} / \mathrm{L}$ Vs. ${ }^{\prime} . V_{ \pm}$ .r r mmom/L, $\mathrm{p}<\cdot .00$ ).

The findings of this study are similar to those of Kareem et al. in $r . . \varepsilon$, who just studied changes of serum TC and TGs in forty type $r$ diabetics with retinopathy compared to $r$. type $r$ diabetics without retinopathy. They showed significantly higher TC and TGs mean values in those with retinopathy at $p<\ldots$. . $^{r v}$.

Several studies have shown conflicting results about role of serum lipids in diabetic retinopathy ${ }^{(r)}$. Sinav et al. reported that while plasma TC and HDL- cholesterol were related to proliferative retinopathy, serum triglycerides were not ${ }^{(r \xi)}$. On the contrary, Weber et al. reported that serum triglycerides, but not cholesterol, were associated with diabetic retinopathy in children with type 1 diabetes. ${ }^{\circ}$. However, Kordonouri et al. showed HDLcholesterol to be the most important variable related to the development of retinal lesions in children with type I diabetes. "r.

It was evident when this study compared diabetics without retinopathy (Group 1) with the healthy controls that diabetics have got higher mean serum TC, TGs and LDLcholesterol values and a significantly lower mean HDL- cholesterol $(p<\ldots \ldots$ for all). This is similar to a study in $r \ldots v$ by Maduka et al. who tried to identify and characterize the lipids and lipoprotein abnormalities associated with $\| \vee$ type $r$ diabetics compared to $0 \wedge$ age matched controls. ${ }^{r v} \quad$ They revealed statistically significant increases $(p<. \cdot 1)$ in the mean values of triglycerides, total 
cholesterol, and VLDL- cholesterol for diabetics compared to their corresponding controls.

This study revealed a significant negative correlation between serum magnesium levels on one hand and fasting serum TGs, TC, and LDL- cholesterol concentrations on the other hand $(p<\ldots$ with all). A study by Corica et al. has also revealed that high plasma triglycerides are independent important correlates of the highly prevalent hypomagnesaemia in diabetic patients besides increased waist circumference and albuminuria. $^{\mathrm{r}}$

The current study, using Forward Stepwise regression analysis, revealed that among the studied parameters hypomagnesaemia, poor glycaemic control (as elevated $\mathrm{HbAlc}$ ) and increasing duration of DM are the most important contributors to the risk of developing diabetic retinopathy as was already shown in Table r.

These findings would rather prove the suggested role of serum magnesium in the metabolic control of DM and the risk of longterm diabetic complications in the presence of hypomagnesaemia. The influence of magnesium depletion in diabetic patients on glycaemic control and dyslipidaemia mainly hypertriglyceridaemia was evident in a study by Yokota et al. in $r . . \leqslant$ when they studied the effects of magnesium supplementation on nine mild type $r$ diabetics. ${ }^{r}$ They revealed a marked decrease of the initially high mean serum triglycerides level after supplementation beside the improvement in the mean blood pressure and the glycaemic control.

In conclusion, magnesium depletion is a significant risk factor for, and a frequent finding in, diabetic retinopathy beside poor glycaemic control, dyslipidaemia (mainly hypertriglyceridaemia), and increasing duration of uncontrolled diabetes. The significant association between hypomag= nesaemia and the high fasting serum levels of TGs, TC, LDL- cholesterol and $\mathrm{HbA}$ 'c would rather support the suggested role for magnesium depletion in the metabolic derangements associated with retinopathy in

१. in Pima Indians and Caucasians. J Clin

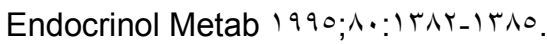

diabetic patients. Further studies on the role of magnesium supplementation for diabetic patients are necessary to investigate the spectrum of metabolic improvements following magnesium therapy and the degree to which the risk of diabetic retinopathy might be reduced.

\section{References}

1. Standing Committee on the Scientific Evaluation of Dietary Reference Intake; Food and Nutrition Board; Institute of Medicine. Dietary reference intakes of calcium, phosphorus, magnesium, vitamin D, and fluoride, vol. `, Washington, DC:

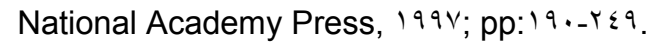

r. Yokota K, Kato M, Shiraishi M, Kageyama S, Sakurai T, Ishibashi K, Yamamoto J, Mimura A, Aihara $\mathrm{K}$, Yokose $\mathrm{T}$, Tajima $\mathrm{N}$. Abnormalities of serum magnesium in the patients with type $r$ diabetes. In: Rayssiguier $\mathrm{Y}$, Mazur A, Durlach J (Eds). Advances in magnesium research: nutrition and health. John Libbey \& Co Ltd, London, UK, r... ); pp:rᄉl-rیr.

r. Yokota K, Kato M, Lister F, Li H, Hayakawa T, Kikuta T, Kageyama S, Tajima N. Clinical Efficacy of magnesium supplementation in patients with type $r$ diabetes. J Am Coll Nutr r. $\varepsilon ; r r(0): 0$. TS-0.9S.

๕. Sharma A, Dabla S, Agrawal RP, Barjatya $H$, Kothari DK. Serum magnesium: An early predictor of course complications of diabetes mellitus. J Indian Med Assoc r...v; $1.0(1)$ : $17,1 \wedge, r \cdot$.

•. American Diabetes Association. Magnesium supplementation in the treatment of diabetes- a consensus statement. Diabetes care 199r;rr:011_01 .

ฯ. Paolisso G, Seheen A, D'Onofrio F, Lefebvre $P$. Magnesium and glucose homeostasis. Diabetologia 199.;rr:011 - $01 \leqslant$.

v. Paolisso G, Barbagallo M, Hypertension, diabetes mellitus, and insulin resistance: the role of intracellular magnesium. Am J

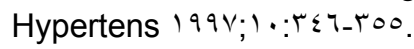

^. Paolisso G, Ravussin E. Intracellular magnesium and insulin resistance: results 
1..Lefebvre PJ, Paolisso G, Scheen AJ. Magnesium and glucose metabolism. Therapie 199ะ;६q:1-V.

11.Resnick LM, Barbagallo M, Gupta RK, Laragh $\mathrm{JH}$. Ionic basis of hypertension in diabetes mellitus: role of hyperglycemia. Am J Hypertens $1994 ; 7: \leqslant 1 \%-\varepsilon / V$.

ir.Sales CH, Pedrosa LFC. Magnesium and diabetes mellitus: Their relation. Clin Nutr r.. т; Y0:00 __07r.

1r. Barbagallo M, Resnick LM, Dominguez LJ, Licata G. Diabetes mellitus, hipertensāo e envenlhecimento: a hipótese iônica das moléstias metabólicocardiovasculares e 0 envelhecimento. Diabetes metab 199^;117-1rA.

1 \&.Fosmark DS, Torjesen PA, Kilhovd BK, Berg TJ, Sandvik L, Hanssen KF. Increased serum levels of the specific advanced glycation end product methylglyoxal-derived hydroimidazolone are associated with retinopathy in patients with type $r$ diabetes mellitus. Metabolism r.. r; 00( r): rrr-rrr.

1॰.Tosiello L. Hypomagnesemia and diabetes mellitus. Arch Intern Med 1997; 107: $11 \leqslant r-$ $11 \leq \Lambda$.

17. Gindler EM, Heth DA. Colorimetric determination with bound "Calmagite" of magnesium in human blood serum. Clin Chem 19v1;1v:77r.

Iv.Khayam- Bashi H, Liu TZ, Walter V. Measurement of serum magnesium with a centrifugal analyzer. Clin Chem $19 \vee \checkmark ; r r$ (r): $r \wedge 9-r q)$.

1^.Stein EA, Myers GL. Lipids, apolipoproteins and lipoproteins. In: Burtis CA, Ashood ER. Teitz Fundamentals of Clinical Chemistry, $\varepsilon^{\text {th }}$ ed., Philadelphia: Saunders, 1997; pp: rvo_ $\varepsilon \cdot 1$.

19. Friedwald WT, Levy RI, Fredrickson DS. Estimation of the concentration of low density lipoprotein cholesterol in plasma without use of the ultracentrifuge. Clin Chem 19Vr;1): $\leqslant$ 9_00r.

r.Maltezos E, Papazoglou D, Exiara T, Kambouromiti G, Antonoglou C. Serum magnesium levels in non- diabetic offspring of patients with Type $r$ diabetes mellitus. Diabetes Nutr Metab ${ } \ldots \varepsilon ; \mid \vee(1)$ : Ir-17.

r.Alzaid AA, Dinneen SF, Moyer TP, Rizza RA. Effects of insulin on plasma magnesium in non insulin- dependent diabetes mellitus: evidence for insulin resistence. J Clin Endocrinol Metab 1990; $\Lambda \cdot: \mid r \vee \tau-1$ r)

$r$ r.Lopez-Ridaura R, Willett WC, Rimm EB , Liu S, Stampfer MJ, Manson JA E, Hu FB. Magnesium Intake and Risk of Type $r$ Diabetes in Men and Women. Diabetes Care $r \ldots \varepsilon ; r \vee: 1 r \varepsilon-1 \varepsilon \cdot$

rr.Ma J, Folsom AR, Melnick SL, Eckfeldt $\mathrm{JH}$, Sharrett AR, Nabulsi AA, Hutchinson RG, Metcalf PA. Associations of serum and dietary magnesium with cardiovascular disease, hypertension, diabetes, insulin, and carotid arterial wall thickness: the ARIC study. J Clin

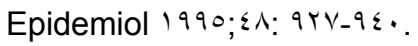

rr. Rodríguez- Moran M, Guerrero- Romero F. Oral magnesium supplementation improves insulin sensitivity and metabolic control in type $r$ diabetic subjects: A randomized double- blind controlled trial. Diabetes Care r..r; r $r(\varepsilon): 11 \leqslant V_{-} 110 r$.

$r \varepsilon$. West KM, Erdreich LJ, Stober JA. A detailed study of risk factors for retinopathy and nephropathy in diabetes. Diabetes 191.; r9:0.1-0.1.

ro. Dhir SP, Dahiya R, Ram J, Dash RJ, Chakravarti RN. Serum lipoprotein cholesterol profile in diabetic retinopathy. Indian J Ophthalmol १৭^乏;rr:^৭- ৭).

ז.. Lyons TJ, Jenkins AJ, Zheng $D$, Lackland DT, McGee D, Garvey WT, Kiein RL, and the DCCT/ EDIC Research Group. Diabetic retinopathy and serum lipoprotein subclasses in the DCCT/ EDIC cohort. JOVS Y. . $\leqslant ; \leqslant 0(r): q 1 \cdot-q 1 \wedge$.

Yv. Kareem I, Jaweed SA, Bardapurkar JS, Patil VP. Study of magnesium, glycated haemoglobin and lipid profile in diabetic retinopathy. Indian $\mathrm{J}$ Clin Biochem $\mathrm{r} . . \xi$; $19(r): 1 r \varepsilon-1 Y v$.

r^.Pankowska E, Staniszewska K. The oxygen availability in children with IDDM.

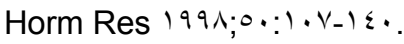


rq. The Diabetes Control and Complications Trial Research Group. The effect of intensive treatment of diabetes on the development and progress of long- term complications in insulin- dependent diabetes mellitus. $\mathrm{N}$ Eng $\mathrm{J}$ Med 199 १;rrq: qVV- 9人.

$r \cdot$. UK Prospective Diabetes Study (UKPDS) Group. Intensive blood- glucose control with sulphonylureas or insulin compared with conventional treatment and risk of complications in patients with type $r$ diabetes. Lancet 199ᄉ; ror:ArV_-ᄉor.

r. Freyberger H, Schifferdecker E, Schatz H. Ruckbildung harter exsudate bei diabetischer hintergrundretinopathie unter therapie mit dem lipidsenker etofibrat.

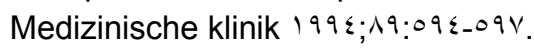

$r$ r. Ebeling P, Koivisto VA. Occurrence and interrelationships of complications in insulin- dependent diabetes in Finland.

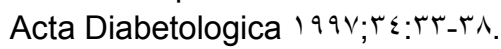

rr. Su D H W, Yeo KT. Diabetic retinopathy and serum lipids. Singapore Med $J Y_{\ldots} \cdot$; \&)( ( ): : $90-$ - 9 .

$r \varepsilon$.Sinav S, Onelge MA, Onelge S, Sinav B. Plasma lipids and lipoproteins in retinopathy of type I (insulin- dependent) diabetic patients. Ann Ophthalmology 1994; r0:7 47.

ro. Weber B, Burgh W. Hartmann R, Horener $G$, Malchus R, Oberdisse U. Risk factors for the development of retinopathy in children and adolescents with type I (insulin- dependent) diabetes mellitus. Diabetologia 1914; $99:$ : r $r 9$.

זч. Kordonouri O, Danne T, Hopfenmuller W, Enders I, Hovener B, Weber B. Lipid profiles and blood pressure: are they risk factors for the development of early background retinopathy and incipient nephropathy in children with insulindependent diabetes mellitus? Acta

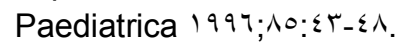

rV.Maduka IC, Onyeanusi JO, Shu EN, Duru C. Lipid and lipoprotein profiles in Nigerian non- insulin- dependent diabetic patients.

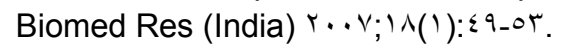

r^. Corica F, Corsonello A, Lentile R, Cucinotta $D$, Benedetto AD, Perticone $F$, Dominguez LJ, Barbagallo M. Serum ionized magnesium levels in relation to metabolic syndrome in type $r$ diabetic patients. J Am Coll Nutr $r \ldots r ; r o(r): r$ I.rio. 